\title{
Analysis of innate defences against Plasmodium falciparum in immunodeficient mice
}

\author{
Ludovic Arnold ${ }^{+1}$, Rajeev Kumar Tyagi ${ }^{\dagger 1}$, Pedro Mejia1,2, Nico Van Rooijen³, Jean-Louis Pérignon¹ and Pierre Druilhe ${ }^{* 1}$
}

\begin{abstract}
Background: Mice with genetic deficiencies in adaptive immunity are used for the grafting of human cells or pathogens, to study human diseases, however, the innate immune responses to xenografts in these mice has received little attention. Using the NOD/SCID Plasmodium falciparum mouse model an analysis of innate defences responsible for the substantial control of $P$. falciparum which remains in such mice, was performed.
\end{abstract}

Methods: NOD/SCID mice undergoing an immunomodulatory protocol that includes, clodronate-loaded liposomes to deplete macrophages and an anti-polymorphonuclear leukocytes antibody, were grafted with human red blood cells and P. falciparum. The systematic and kinetic analysis of the remaining innate immune responses included the number and phenotype of peripheral blood leukocytes as well as inflammatory cytokines/chemokines released in periphery. The innate responses towards the murine parasite Plasmodium yoelii were used as a control.

Results: Results show that 1) P. falciparum induces a strong inflammation characterized by an increase in circulating leukocytes and the release of inflammatory cytokines; 2 ) in contrast, the rodent parasite $P$. yoelii, induces a far more moderate inflammation; 3) human red blood cells and the anti-inflammatory agents employed induce low-grade inflammation; and 4) macrophages seem to bear the most critical function in controlling $P$. falciparum survival in those mice, whereas polymorphonuclear and NK cells have only a minor role.

Conclusions: Despite the use of an immunomodulatory treatment, immunodeficient NOD/SCID mice are still able to mount substantial innate responses that seem to be correlated with parasite clearance. Those results bring new insights on the ability of innate immunity from immunodeficient mice to control xenografts of cells of human origin and human pathogens.

\section{Background}

Defences against foreign cells, including pathogens, rely on both innate or non-adaptive responses, and adaptive or antigen-specific immune responses. However, modern immunology has focused primarily or almost exclusively on the latter.

Therefore, various strains of mice having a genetic deficiency in cells responsible for adaptive immunity (i.e. $\mathrm{T}$ and B lymphocytes) have been selected, which have been used for the grafting of xenogenic cells, particularly those of a human origin. Indeed, the vast majority of these studies have focused on the grafting of human lymphocytes, haematopoietic stem cells and to a lesser extent

\footnotetext{
* Correspondence: druilhe@pasteur.fr

1 Laboratoire de Parasitologie Bio-Médicale, Institut Pasteur, 28, rue du Dr Roux, 75015 Paris, France

+ Contributed equally

Full list of author information is available at the end of the article
}

tumor cells [1]. However, it was previously shown that one can take advantage of these immunocompromized mice to develop a mouse model for human malaria.

The initial report that bovine red blood cells (RBC) injected intra-peritoneally in SCID mice could cross the peritoneum and colonize the peripheral blood [2] was an incentive to repeat the experiment using human red blood cells (HuRBC). Although there was regrettably no understanding of the underlying mechanism of transport through the peritoneum, SCID mice harbouring up to 70 - $80 \%$ HuRBC among total RBC in mice peripheral blood were obtained [3].

However, when Plasmodium falciparum was injected into SCID mice, the parasites became pycnotic within hours in erythrocytes. After excluding a potential toxicity of mouse serum by in vitro methods, [3], it was hypothesized that innate immune defences could constitute the main limiting factor in parasite survival, and this was 
confirmed by employing agents able to control macrophages (MP) and other cells involved in innate defences $[4,5]$. Further steps were performed in an empirical manner. The model was improved by moving from the original SCID mouse to the NIHIII (Beige Xid Nude) mouse, then to the NOD/SCID mouse that have more defective innate immunity, and by identifying two components which, when combined, allowed to obtain a stable $P$. falciparum parasitaemia in some of the NOD/SCID mice [6] (namely: liposomes encapsulating dichloromethylenediphosphonate, named clo-lip [5] and a monoclonal antibody (NIMP-14) [4] directed to mouse polymorphonuclear cells (PMN)).

Though this empirical approach demonstrated the feasibility of the objective, and could be applied to vaccine development [6,7] and drug screening [8], the control of innate defences was far from optimal in this $P$. falciparum blood stage rodent model. Indeed, the P. falciparum parasitaemia remained stable for extended periods of time, up to four months only in a minor subset of mice, whereas it was cleared within a few days in the majority of the animals.

The above data stress the importance of innate defences and are in agreement with long standing observations made in humans. However, despite their crucial importance innate defences have been far less studied than adaptive responses, and remain poorly known. Innate responses in P. falciparum infected patients were recently analysed in detail and this unveiled several dramatic modifications in the phenotypes and functions of blood monocyte/macrophage populations [9].

To complement the above descriptive analysis in humans by an experimental approach in a model, it was decided to perform in the $P$. falciparum NOD/SCID model a systematic and stepwise analysis of innate cell responses and inflammation mediators produced in response to the grafting of HuRBC, of P. falciparum, as well as to agents employed to control innate defences. Results bring new insights about the role and potency of innate defences against human xenografts, such as HuRBC, and human pathogens, such as P. falciparum.

\section{Methods}

Mice

Two to six months old male and female NOD/SCID mice were used. They were purchased from Charles River, and kept in an A3 animal house, i.e. in sterile isolators. They were housed in sterilized cages equipped with filter tops during the experimentation. Mice were provided with autoclaved tap water and a $\gamma$-irradiated pelleted diet ad libitum. They were manipulated under pathogen free conditions using laminar flux hoods. All animals were treated according to the French legislation.

\section{Human red blood cells}

Human whole blood was provided by the French blood bank (Etablissement français du sang, Paris, France). Blood donors had no history of malaria and all the blood groups were used without observing any difference on parasite survival. Whole blood was washed three times by centrifugation at $900 \times \mathrm{g}, 5$ minutes at room temperature and buffy coat was separated in order to eliminate white blood cells and platelets. Packed HuRBC were suspended in SAGM (Adenine, Glucose and mannitol solution) and kept at $4^{\circ} \mathrm{C}$ for a maximum of 2 weeks. Before use HuRBC were washed three times in RPMI-1640 medium (Gibco/ BRL, Grand Island, N.Y.) supplemented with $1 \mathrm{mg}$ hypoxanthine per liter (Sigma, St Louis, MO) and warmed 10 minutes at $37^{\circ} \mathrm{C}$.

\section{Parasite cultures}

The $P$. falciparum 3D7 clone was employed in this study. This parasite strain was maintained in vitro at $5 \%$ haematocrit in complete culture medium at $37^{\circ} \mathrm{C}$ in a candle jar. This medium contained RPMI-1640 medium (Gibco/ BRL), $35 \mathrm{mM}$ HEPES (Sigma), $24 \mathrm{mM} \mathrm{NaHCO} 3,0.5 \%$ albumax (Gibco/BRL) and $1 \mathrm{mg}$ of hypoxanthine (Sigma) per liter. Cryopreserved parasites were thawed using the glycerol/sorbitol method [10] and used for the further experiments.

A non-lethal rodent parasite strain Plasmodium yoelii XNL1.1 was preserved in $500 \mu \mathrm{l}$ aliquot of cryo-preserving buffer at $-80^{\circ} \mathrm{C}$ at $22 \%$ parasitaemia. The strain was thawed at room temperature, diluted twice in RPMI-1640 medium followed by the injection of $50 \times 10^{6}$ parasite directly into the mice.

\section{Immunomodulatory agents and suppression of innate immunity}

Numerous attempts were made to increase the success rate of the grafting of infected RBC. Clo-lip (provided by $\mathrm{N}$. Van Rooijen) was injected through intraperitoneal (i.p.) route in order to reduce the number of tissue MP, as described previously [5]. The anti-PMN monoclonal antibody NIMP-R14 [4] was purified from a hybridoma kindly provided by Dr. M. Strath (National Institute for Medical Research, London, UK). Its activity was compared to that of two other anti-PMN monoclonal antibodies: RB6-8C5 (purified from the hybridoma kindly provided by Geneviève Milon (Institut Pasteur, Paris, France) and 1A8 (purchased from BioXcell, Lebanon). The NIMP-R14 monoclonal antibody was used in all the studies, unless specified. Various agents (all purchased at Sigma, unless specified) were used to further reduce innate immunity such as dexamethasone $(1-5 \mathrm{mg} / \mathrm{Kg} /$ day), TGF- $\beta 100$ ng - 1 g/day) (PeproTech, Rocky Hill, $\mathrm{NJ})$, cyclophosphamide (75 mg/kg/day), cisplatinium (1$10 \mathrm{mg} / \mathrm{Kg} /$ day), and TM $\beta-1$ monoclonal antibody that 
targets NK cells ( $1 \mathrm{mg} / \mathrm{kg} /$ day). The effect of splenectomy and of irradiation (100 - 300 cGy) was also tested. Other experiments evaluated the addition of metabolic agents such as pABA ( $400 \mathrm{mg} / \mathrm{kg} /$ day), and folinic acid $(400 \mathrm{mg} /$ $\mathrm{kg} /$ day), or of antioxidants, such as vitamin $\mathrm{E}(20 \mathrm{mg} / \mathrm{Kg} /$ day; Nepalm, Cenexi, Fontenay sous bois), N-acetyl cysteine (100 mg/kg/day), trolox (4 - $100 \mathrm{mg} / \mathrm{kg} /$ day), 8aminoguanidine $(100 \mathrm{mg} / \mathrm{Kg} /$ day $)$.

\section{Chemical immunomodulation protocol and mouse infection}

In the current study, a previously described immunomodulation protocol was employed [11], modified as described in [12]. On day -13, each mouse received a dose of $10 \mathrm{mg} / \mathrm{kg}$ of mAb NIMP-R14 by i.p. injection. On day 12 , each mouse received $0.2 \mathrm{ml}$ of the suspension of clolip by the same route. On days $-9,-6,-3$ each mouse received $0.5 \mathrm{ml}$ of HuRBC i.p. mixed with a dose of 10 $\mathrm{mg} / \mathrm{kg}$ of mAb NIMP-R14 and $0.2 \mathrm{ml}$ of clo-lip. On day 0 mice were infected with $500 \mu \mathrm{l} \mathrm{HuRBC}$ parasitized by $P$. falciparum at a parasitaemia of $1 \%$ (all the developmental forms, i.e. trophozoite, schizont and rings, were present) mixed with a dose of $10 \mathrm{mg} / \mathrm{kg}$ of NIMP-R14 antibody. Afterwards, a dose of $10 \mathrm{mg} / \mathrm{kg}$ of antibody NIMP-R14, $0.2 \mathrm{ml}$ of clo-lip and $0.5 \mathrm{ml}$ of HuRBC was injected i.p. at 3 days interval, until the end of the study. The follow-up of the infection was performed by daily Giemsa stained thin blood films drawn from the tail vein.

\section{Haematological parameters and grafting of $P$. falciparum- HuRBC}

The study blood samples were collected from mice retroorbital sinus on heparin. Various haematological parameters such as haematocrit, leukocyte number and phenotype (Ly-6C APC, Ly-6G APC (Miltenyi Biotec, Germany), CD115 PE, CD43 FITC, CD62L FITC, CD11b FITC, DX5 FITC, CD122 PE (BD Biosciences, UK) in peripheral blood samples were monitored, as well as the phenotype characterization of monocytes $\left(\mathrm{CD} 11 \mathrm{~b}^{+}\right.$, CD115+), inflammatory monocytes (CD43-, CD62L+, Ly-

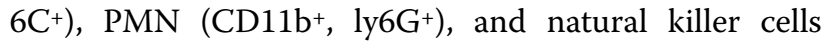
$\left(\mathrm{DX} 5^{+}, \mathrm{CD} 122^{+}\right)$. Total leukocyte number (leukocytes $/ \mu \mathrm{l}$ blood) was evaluated by lysing $20 \mu \mathrm{l}$ of total blood with BD FACS ${ }^{\text {mi }}$ Lysing solution, and counting on Malassez haematocytometer. Since successfully grafted mice have a significant, but variable, percentage of HuRBC in their peripheral blood, parasitaemia in mice was expressed as the overall percentage of $P$. falciparum infected $R B C$ among total RBC, i.e. both human and mouse RBC observed in thin blood smears. In addition, the peritoneal blood parasitaemia was measured in the smears drawn from the peritoneum. The percentage of HuRBC in the peripheral blood of mice was determined by an immunofluorescence technique using a FITC labeled anti-human glycophorin A monoclonal antibody (DAKO, Denmark).

\section{Assay of cytokines and chemokine}

100-150 $\mu \mathrm{l}$ blood samples were collected from the retroorbital sinus with the help of Pasteur pipette, and sera were stored at $-80^{\circ} \mathrm{C}$. Cytokines (IL-6, MCP-1, IFN $\gamma$, TNF $\alpha$, IL-12p70 and IL-10) were quantified using the $\mathrm{BD}^{\mathrm{mm}}$ Cytometric Bead Array mouse inflammatory kit following the manufacturer's recommendations.

\section{Statistical analysis}

The paired test was used for statistical analysis. P values of less than 0.05 were considered significant. In the results section only differences reaching significance are mentioned.

\section{Results}

Various patterns of peripheral blood parasitaemia are observed in NOD/SCID mice

Although stable long-lasting parasitaemia could be obtained and employed for various applications $[8,11]$ the pattern of parasitaemia has never been homogeneous, i.e. varied greatly from one animal to the other, and the various attempts to modify the protocol failed to improve results significantly. For instance, among a total of 84 mice studied recently under rigorous and well-controlled conditions using the standard immunomodulation protocol described above, four different patterns of peripheral blood parasitaemia could be described (summarized in Figure 1). Following a single infection by $P$. falciparum, $17 \%$ of mice remained parasitologically negative, $34 \%$ showed a transient parasitaemia lasting for $c a .12$ days post-infection, $12 \%$ showed a stable parasitaemia for more than 20 days and 37\% showed an almost total para-

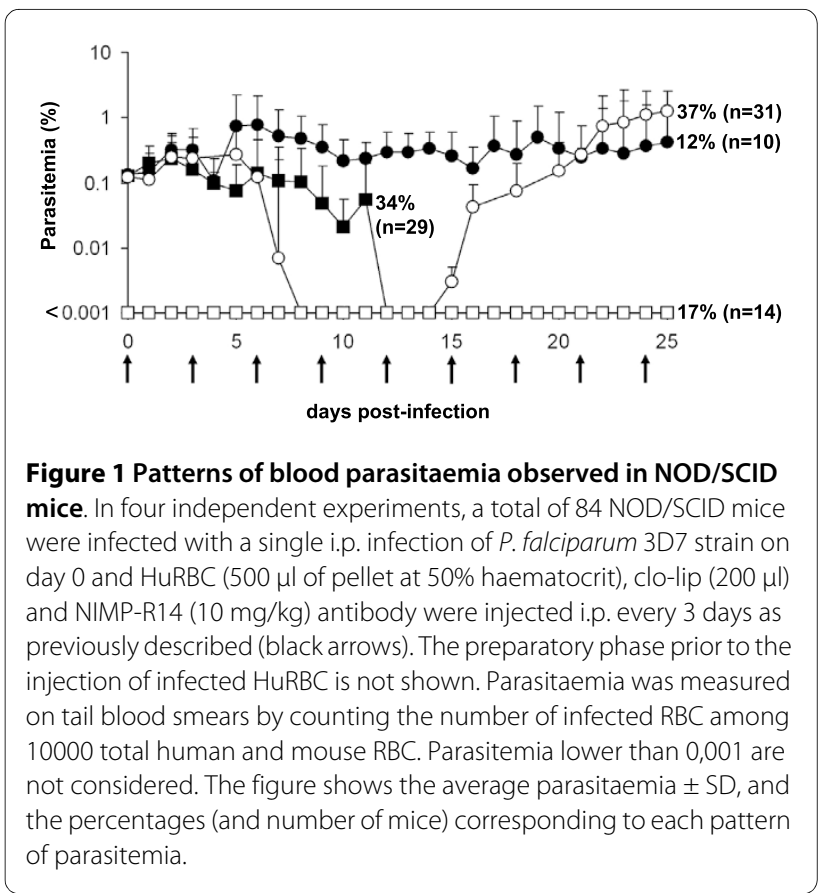


site clearance from peripheral blood, however followed by a re-emergence a few days later, without new parasite inoculation, i.e. a second wave of parasitaemia lasting for the life-span of the animal. The sequence of events of the latter pattern considered the most informative, was selected for further analysis.

Various modifications to the standard protocol were assessed, and resulted only in differences in the proportion of mice presenting the four patterns of parasitaemia described above. These modifications include: 1) variations in the dose and schedule of administration of the different components (i.e. infected and uninfected HuRBC, clo-lip and NIMP-R14, including modifications proposed by others [12]); 2) use of various agents to reduce innate immunity, such as cyclophosphamide, cisplatinium, irradiation, dexamethasone, TGF- $\beta$, splenectomy, TM $\beta-1$ antibody targeting NK cells 3 ) Addition of metabolic precursors such as PABA, folinic acid to supply nutritive factors for the parasite 4) Addition of antioxidants such as vitamin E, N-acetyl cysteine (NAC), trolox, 8-aminoguanidine. These empirical approaches never brought a significant or reproducible improvement of parasite survival in NOD/SCID mice.

These results raise the question of which factor(s) are critical to control in order to obtain a stable parasitaemia and prompted the launch of a detailed analysis of the remaining innate immune defences, mainly MP and PMN.

\section{The strong inflammation induced by $P$. falciparum is associated with parasite clearance}

In mice showing a recrudescence (fourth pattern described above, which was thought to be the most discriminating, see Figure 1) the following parameters were analysed in kinetic manner: 1) the numbers and phenotype of blood leukocyte subsets, 2) various cytokines serum levels, 3) HuRBC grafting in the peripheral blood, together with 4) parasitaemia.

Results, summarized in Figure 2A, show that, whereas parasitaemia in peritoneal blood remains stable over time, conversely, peripheral blood parasitaemia decreases markedly. This decrease is related to a major clearance of HuRBC in this compartment, despite repeated blood injections, which is parasite-dependant since the numbers of circulating HuRBC in control, uninfected mice, remain stable (see below).

The parasite was found to induce a very potent proinflammatory effect characterized by a transient increase in peripheral leukocytes numbers mostly monocytes (MO) $(1690 \pm 1080 \mathrm{MO} / \mu \mathrm{l}$ on day 7 post-infection $v s 290$ \pm 125 on day 0 , i.e. 5.8 fold increase; $\mathrm{P}<0.006)$ and to a lesser extent PMN $(3000 \pm 1500 \mathrm{PMN} / \mu$ l on day 3 postinfection $v s 2100 \pm 750$ on day 0, i.e. 1.4 fold increase; not significant) (Figure 2B). Moreover, during the first few

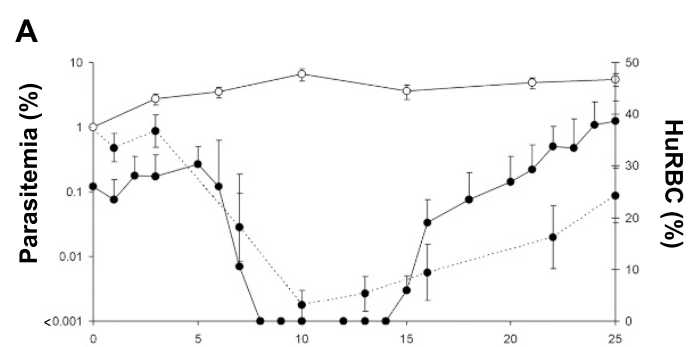

B
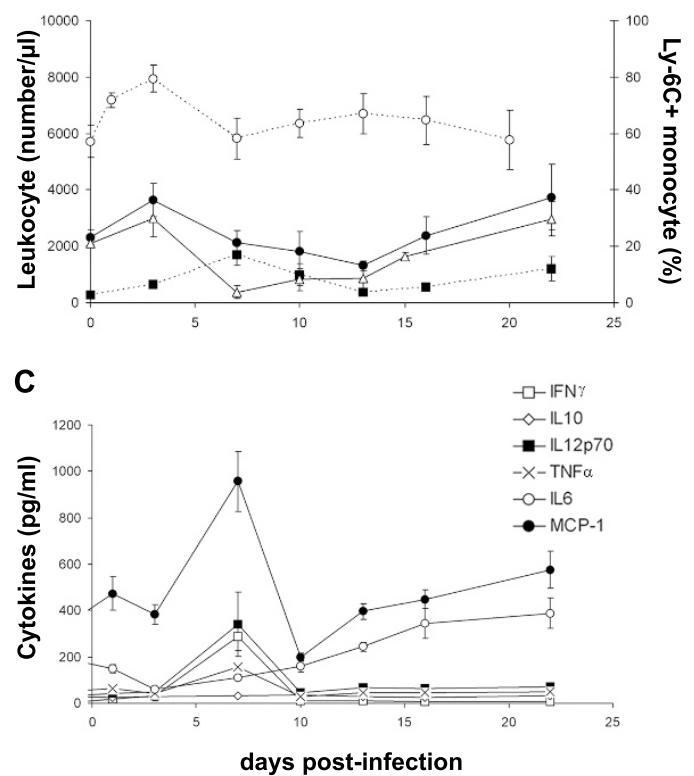

D

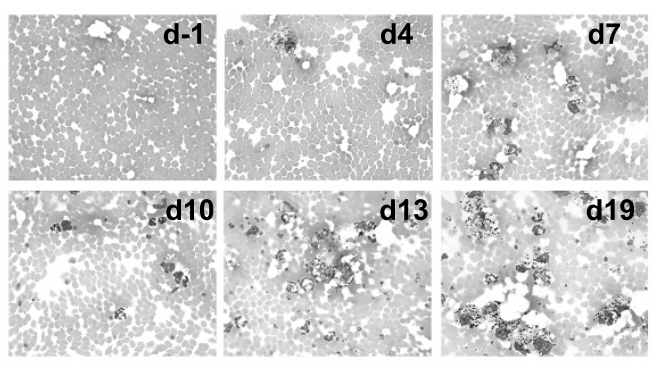

Figure $2 P$. falciparum is highly pro-inflammatory. (A) Peripheral (plain circles) and peritoneal (open circles) parasitaemia (average of 31 mice \pm SEM) counted on blood smears and percentage of human glycophorin A+ RBC grafted in mouse peripheral blood detected by FACS among total RBC (full circle, dotted line). Parasitemia lower than 0,001 are not considered. (B) Total number of leukocyte per $\mu$ l of blood (plain circle) at different times post-infection. The numbers of $\mathrm{CD} 11 \mathrm{~b}+\mathrm{F} 4 / 80^{+}$ monocytes (black square, dotted line) and CD11 b+ Ly- $6 G^{+}$PMN (white triangle) were calculated from the percentages obtained by FACS analysis. The percentage of CD43-CD62L+ Ly-6C+inflammatory monocytes was also assessed by FACS (open circle, dotted line). (C) Cytokines/ chemokine levels were estimated using the CBA mouse inflammatory cytokines kit by FACS. (D) Representative peritoneal blood smears showing the progressive phagocyte recruitment following $P$. falciparum infection. Results represent the means \pm SEM from 3 distinct experiments ( $n=14$ mice). 
days following the infection, a transient increase (Figure 2B) in blood MO having an inflammatory phenotype CD43- CD62L ${ }^{+}$Ly-6C ${ }^{+}$was observed (57.2 $\pm 12.7 \%$ of MO on day -1 before infection vs $80 \pm 11 \%$ on day 3 postinfection; $\mathrm{P}<0.03$ ) (the $\mathrm{Gr}-1$ antigen is not expressed on NOD/SCID MO surface). In addition, the parasite induces a major recruitment of leukocytes in the peritoneal cavity as compared to controls receiving uninfected HuRBC (Figure 2D).

The peak of blood MO was associated with a peak of secretion of several inflammatory cytokines such as IL$12 \mathrm{p} 70(342 \pm 520 \mathrm{pg} / \mathrm{ml}$ on day 7 post-infection $v s 33 \pm$ $6.5 \mathrm{pg} / \mathrm{ml}$ on day -1 before infection), $\operatorname{IFN\gamma }(290 \pm 215 \mathrm{pg} /$ $\mathrm{ml}$ on day 7 vs $5 \pm 2.2 \mathrm{pg} / \mathrm{ml}$ on day -1$)$ and TNFa (155 \pm $53 \mathrm{pg} / \mathrm{ml}$ on day 7 vs $53 \pm 26 \mathrm{pg} / \mathrm{ml}$ on day -1) or chemokine such as MCP-1 (from $355 \pm 290 \mathrm{pg} / \mathrm{ml}$ on day -1 to $960 \pm 480 \mathrm{pg} / \mathrm{ml}$ on day 7 post-infection $)(\mathrm{P}<0.009)$.

Results attest of the strong inflammation induced by the parasite; however the latter is transient, (Figure 2C) and accordingly the number of leukocyte decreases to reach values close to the steady state.

The decrease in parasite-induced inflammation was followed by a new increase in HuRBC numbers in peripheral blood, which understandably correlated with a recrudescence of $P$. falciparum blood parasitaemia. This second wave of parasitaemia itself induced an increase of leukocyte counts, of IL-6 and MCP-1, however not of IL$12 \mathrm{p} 70, \mathrm{IFN} \gamma$ and TNF $\alpha$, and in addition, was not associated with a re-emergence of inflammatory MO. Hence, the secondary parasitaemia was less pro-inflammatory than the first. This also point to an important role for inflammatory $\mathrm{MO}$ in the initial clearance of uninfected and $P$. falciparum infected HuRBC.

\section{Plasmodium yoelii is far less pro-inflammatory than $P$. \\ falciparum}

Innate immune responses triggered by $P$. falciparum were compared with those elicited by the murine non-lethal parasite $P$. yoelii XNL 1.1 strain. In contrast to $P$. falciparum, $P$. yoelii induced an exponential increase in parasitaemia in immunodeficient NOD/SCID mice reaching more than $60 \%$ within two weeks (Figure 3A), accompanied by a major drop in haematocrit ( 52 to $18 \%$ by week 2 ), and ultimately led to the death of the animals. An increase in the numbers of circulating leukocytes occurred, but was delayed, until parasitaemia was already high (ca. 10\%) (Figures 3A and 3B). The number of leukocytes increased 3.5 fold from day 7 (2600 \pm 800 leukocytes $/ \mu \mathrm{l})$ to day $15(9100 \pm 2250)$ post-infection $(\mathrm{P}<$ $0.004)$. This was mainly due to a 4.2 fold increase in PMN from day $11(1060 \pm 630)$ to $15(5500 \pm 1300)(\mathrm{P}<0.008)$. There was a major, 7.1 fold, increase of NK cells from day $7(95 \pm 50 \mathrm{NK}$ cells $/ \mu \mathrm{l})$ to day $15(675 \pm 180)(\mathrm{P}<0.001)$, and a lower, 2.2 fold, increase in MO from day 4 (560 \pm $230 \mathrm{MO} / \mu \mathrm{l})$ to $7(1200 \pm 390)(\mathrm{P}<0.013)$.
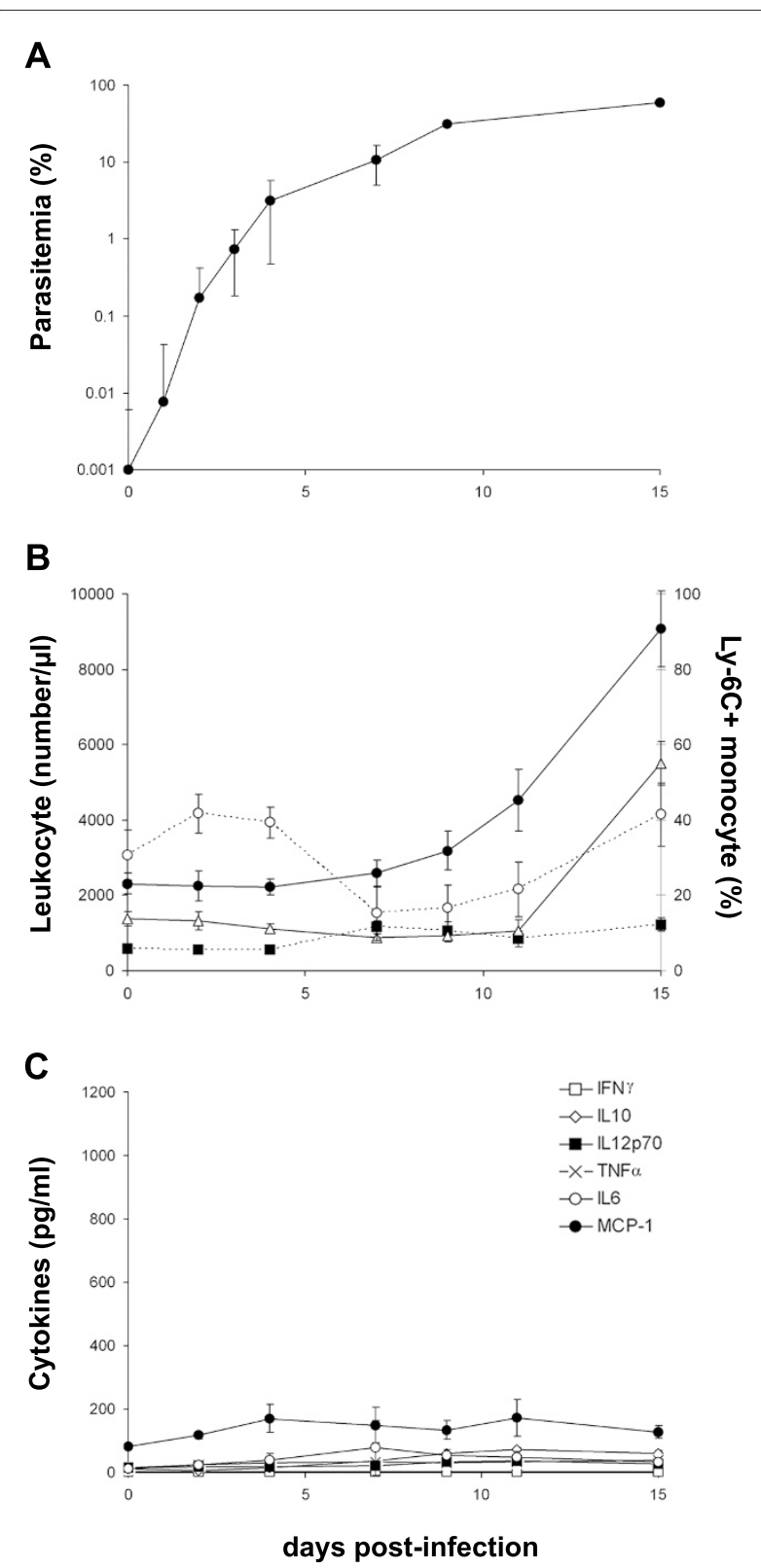

Figure $3 \mathrm{P}$. yoelii is far less pro-inflammatory than P. falciparum $P$. yoelii non lethal XNL 1.1 strain was injected i.p. in NOD/SCID mice and the same parameters as in $P$. falciparum infected mice were assessed (see the legend of figure 2). (A) Peripheral blood parasitaemia; (B) Total number of leukocyte per $\mu \mathrm{l}$ of blood (plain circle) at different time post-infection. The numbers of $\mathrm{CD} 11 \mathrm{~b}+\mathrm{F} 4 / 80^{+}$monocytes (black square, line dot) and CD11 $b^{+} L y-6 G^{+} P M N$ (white triangle) were calculated from the percentages obtained by FACS analysis. The percentage of CD43-CD62L+Ly-6C+inflammatory monocytes was also assessed by FACS (open circle, dotted line); (C) Cytokines/chemokine levels determined using the CBA mouse inflammatory cytokines kit. Results represent the means \pm SEM from 2 distinct experiments ( $n=5$ mice).

Plasmodium yoelii infection did not induce the strong inflammation characteristic of $P$. falciparum. Only MCP1 was detected to a significant level $(145 \mathrm{pg} / \mathrm{ml}$ till the end of the study) but its basal level was already elevated (80 
$\mathrm{pg} / \mathrm{ml}$ ) (Figure 3C). The other cytokines assayed did not show any significant increase as compared to basal level (Figure 3C). Moreover, P. yoelii did not induce the strong increase of CD43- $\mathrm{CD}^{2} \mathrm{~L}^{+} \mathrm{Ly}-6 \mathrm{C}^{+}$inflammatory $\mathrm{MO}$ which was very significant with $P$. falciparum (Figure 2B), but only several moderate variations (i.e. a small initial increase from $30.6 \pm 6.5 \%$ on day 0 to $41.7 \pm 5.2 \%$ on day 2 post-infection $(\mathrm{P}<0.0045)$ followed by a temporary decrease, $15.2 \pm 7.3 \%$ on day 7 post-infection $(\mathrm{P}<0.0045)$ then by a new increase to reach steady state value on day 15 post-infection) (Figure 3B). In the absence of adaptive immune responses, all mice infected with $P$. yoelii died between day 16 to day 20 post-inoculation (not shown).

\section{HuRBC, and anti-inflammatory agents, induce low-grade inflammation}

Considering the indications that inflammation was related to the clearance of the parasite, it was decided to examine whether HuRBC, clo-lip and NIMP-R14 antibody also induce inflammation. The effects of each component, injected i.p. upon 1) the number and phenotype of blood leukocytes, and 2) cytokines serum levels, were examined. The inflammatory effect of HuRBC was not unexpected, as it represents a heterologous graft. The i.p. injection of HuRBC induced an increase in leukocyte numbers (Figure 4A) $(\mathrm{P}<0.003$ between day 0 and day 3$)$ mainly PMN and to a lesser extent MO and NK cells (data not shown). The inflammatory MO subset increased transiently to peak at $76 \%$ of total MO 10 hours post infection $(\mathrm{P}<0.009)$, and then progressively decreased to basal level (Figure 4B). HuRBC grafting also led to a transient secretion of IL-6 (732 \pm 51 vs $47 \pm 14.7 \mathrm{pg} / \mathrm{ml} ; \mathrm{P}<$ $0.003)$ and TNFo $(216 \pm 51 \mathrm{pg} / \mathrm{ml}$ vs $75 \pm 79 \mathrm{pg} / \mathrm{ml} ; \mathrm{P}<$ 0.1 ) (Figures $4 \mathrm{C}$ and $4 \mathrm{E}$ ), without substantial modifications of MCP-1, IL-10, IL-12p70 or IFNY.

Unexpectedly, it was observed that clo-lip induce a fast and strong inflammatory reaction. Indeed, as soon as three hours post liposomes injection, the number of circulating leukocyte increased by 6.8 fold (Figure 4A) (MO 3.14 fold, PMN 8.8 fold and NK 3.07 fold) $(\mathrm{P}<0.01)$, and thereafter, decreased but slowly (remaining four times higher than basal level 48 hours post-injection). In addition, clo-lip induced an increase of the "inflammatory" MO subset (CD43- CD62 $\left.\mathrm{L}^{+} \mathrm{Ly}-6 \mathrm{C}^{+}\right)$that lasted for more than three days (Figure $4 \mathrm{~B})(\mathrm{P}<0.001)$. Clo-lip injection also led to a transient release of IL- $6(777 \pm 445 v s 48 \pm 30$ $\mathrm{pg} / \mathrm{ml}$ at 3 hours post-injection) (Figure $4 \mathrm{C})(\mathrm{P}<0.03)$.

Finally, the anti-PMN monoclonal antibody NIMP-R14 had a modest effect on the number of leukocytes and on the percentage of inflammatory $\mathrm{MO}$, but was the strongest inducer of IL-6 $(1054 \pm 292$ vs $30 \pm 7 \mathrm{pg} / \mathrm{ml}$ at 3 hours post-injection) and of MCP-1 (2425 $\pm 760 \mathrm{pg} / \mathrm{ml}$ at 3 hours post-injection) (Figure $4 \mathrm{C}$ and $4 \mathrm{D}$ ), and also induced the release of $\operatorname{TNF}(133 \pm 19$ vs $24 \pm 3.7 \mathrm{pg} / \mathrm{ml}$ at 3 hours post-injection) (Figure $4 \mathrm{E})(\mathrm{P}<0.04)$.
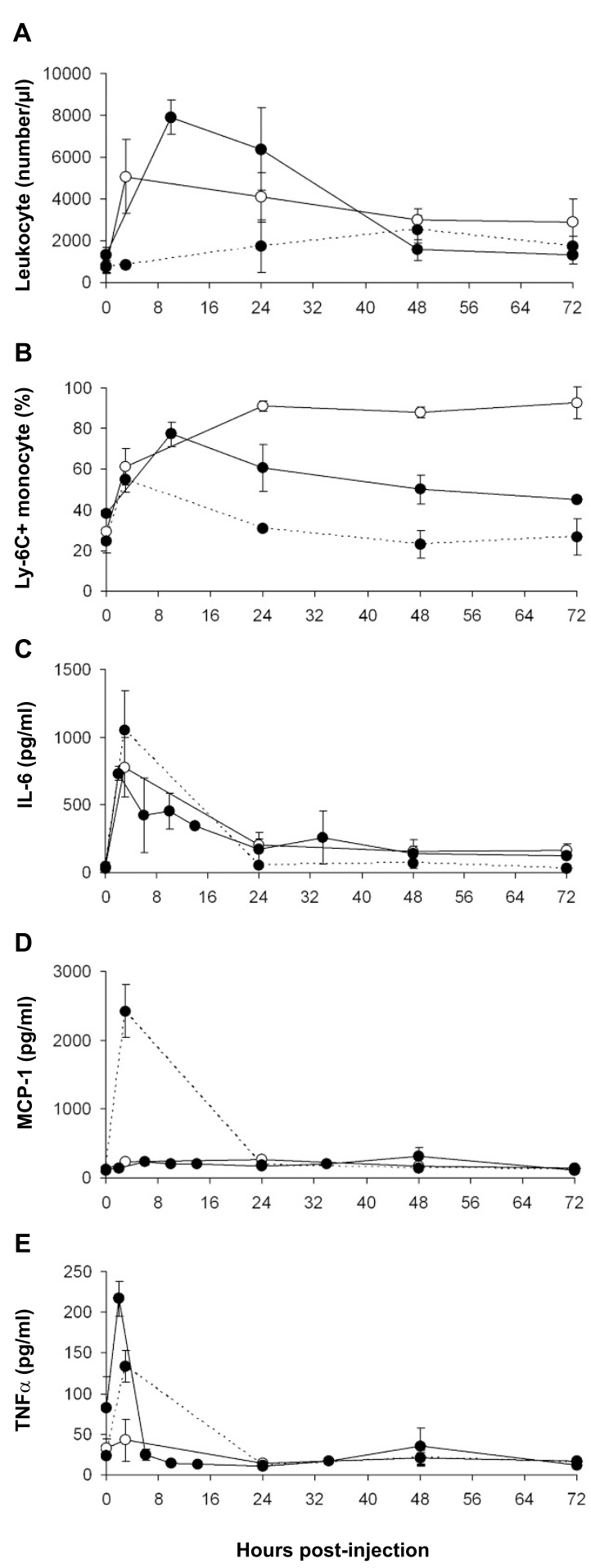

Figure 4 HuRBC, clo-lip and NIMP-R14 antibody are pro-inflammatory. HuRBC (full circle, plain line), clo-lip (open circle) and NIMPR14 antibody (full circle, dotted line) were injected once in the peritoneum at hour 0 , at doses identical to those used for the whole immunomodulation protocol. Leukocyte number (A), CD43-CD62 L + Ly-6C+ inflammatory monocytes (B) and inflammatory cytokines/chemokine (C-E) were assessed in mouse peripheral blood by FACS. Results are the means $\pm S D$. from groups of 4 mice. 
Altogether these results indicate that the immunomodulators clo-lip and NIMP-R14 antibody, which have previously been shown to be indispensable to the grafting of $P$. falciparum, actually reduce innate responses, though at the expense of a transient but substantial inflammation.

The repeated injection of HuRBC, clo-lip and anti-PMN reduces inflammation and improves HuRBC grafting

The intriguing results above led to analyse the events spanning the 13 days of the immunomodulation protocol preceding the injection of the parasite. This protocol consists in four co-injections of HuRBC, together with clo-lip and NIMP-R14 antibody, to prepare the host to the infection as suggested by others [12]. A progressive decrease of inflammation during the immunomodulation protocol was observed. At the end, the levels of cytokines were lower (Figure $5 \mathrm{~B}$ ) than those induced by a single injection, for IL-6 (146 \pm 43 vs $527 \pm 175$ pg/ml), MCP-1 (322 \pm 31 vs $580 \pm 58 \mathrm{pg} / \mathrm{ml})$, and $\mathrm{TNF}(40 \pm 12$ vs $72 \pm 12 \mathrm{pg} /$ $\mathrm{ml})(\mathrm{P}<0.03)$. The number of leukocytes and the percentage of CD43- CD62L $+\mathrm{Ly}-6 \mathrm{C}+\mathrm{MO}$ also decreased over time (Figures $5 \mathrm{C}$ and $5 \mathrm{D})(\mathrm{P}<0.05)$. These changes resulted in an improved grafting of HuRBC as compared to a single injection (35.6 $\pm 14.3 \%$ vs ca. $10 \%$ ) (Figure $5 \mathrm{~A}$ ).

\section{MO/MP are critical in controlling P. falciparum and HuRBC grafting in NOD/SCID mice}

An attempt was made to identify the cell subset most critical in controlling $P$. falciparum in NOD/SCID mice. NK cells are less numerous and functionally deficient in NOD/SCID as compared to BXN mice. In addition, their depletion by the TM $\beta-1$ antibody did not result in any improvement. Both observations do not point to a major role of these cells (data not shown).

The rise in leukocyte numbers induced by $P$. falciparum is predominantly due to an important increase in PMN numbers, leading to legitimately suspect their involvement. To explore the role of PMN, three different monoclonal antibodies were employed, that differ in their efficiency to deplete PMN, namely $1 \mathrm{~A} 8, \mathrm{RB} 6-8 \mathrm{C} 5$ and NIMP-R14 antibodies. $1 \mathrm{~A} 8$ antibody led to a major depletion of PMN for a period of ten days after infection, whereas the other two had only a moderate effect. Despite these differences, the resulting parasitaemia were essentially similar, which does not designate PMN as a main effector against infected HuRBC (Additional file 1).

The above results led to address the role of $\mathrm{MO}$ and of the large MP derived from them. Firstly, MP is the main subset of phagocytes recruited into the peritoneum all over the course of infection (Figure 6A) $(\mathrm{P}<0.05)$. Secondly, they were found to be the most active, and in particular more active than PMN at ingesting both infected and non-infected HuRBC in the peritoneum (Figure 6B and $6 \mathrm{C}$ upper panel) but also in the spleen (Figure $6 \mathrm{C}$
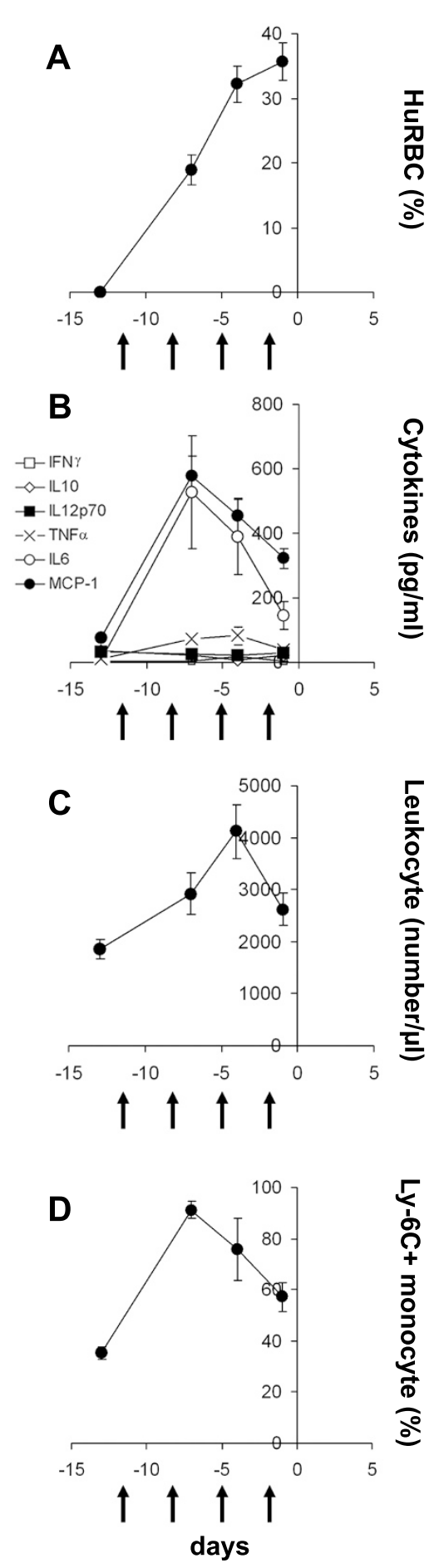

Figure $5 \mathrm{Graft}$ of HuRBC and markers of inflammation during the immunomodulation protocol. (A) The percentage of HuRBC grafted in mouse peripheral blood was assessed by FACS by using an anti-human glycophorin A antibody, after several co-injections of HuRBC, clolip and NIMP-R14 antibody into the peritoneum (black arrows). (B) Cytokines/chemokines were assessed in mouse sera by FACS using the CBA mouse inflammatory cytokines kit. (C) Leukocyte number. (D) CD43-CD62L+ Ly-6C+ inflammatory monocytes were assessed by FACS. Results are means \pm SEM of 2 experiments ( $n=15$ mice). 

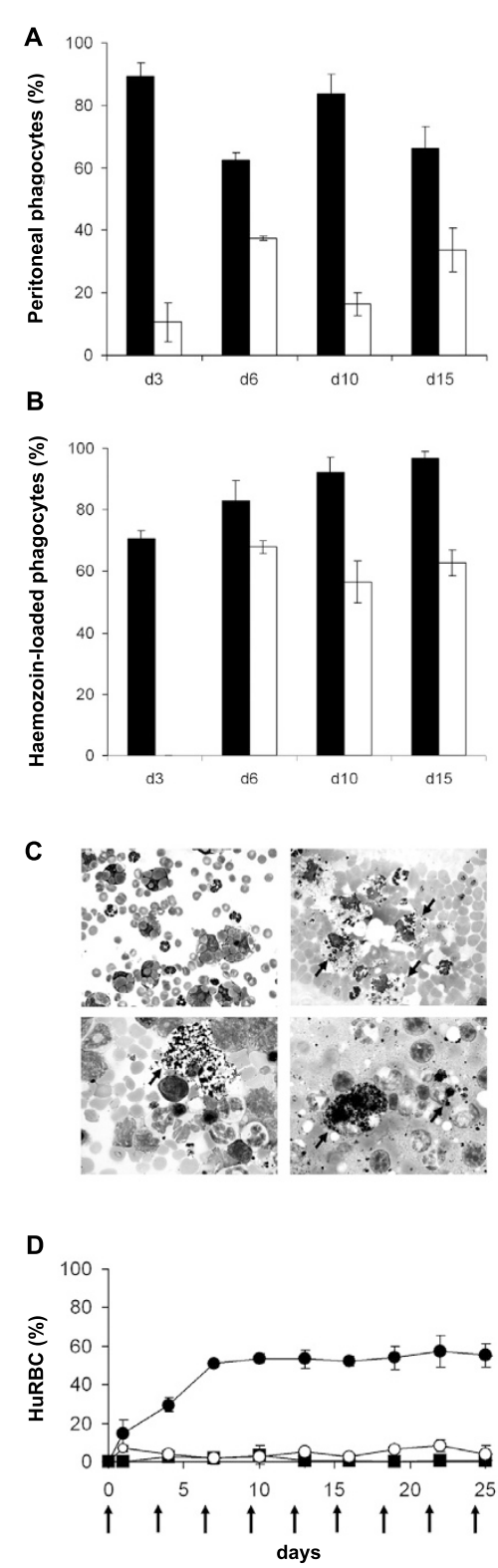

Figure 6 Evaluation of the role of PMN, and of monocytes/macrophages, in the graft of infected and non-infected HuRBC. A peritoneal smear was drawn at different times post-infection in order to assess the phenotype of peritoneal phagocytes. (A) MP (black bar) and PMN (white bar) were identified by microscopy in order to determine the percentage of each subset among the total number of phagocytes counted on the smear (at least 500). (B) Percentages of MP (black bar) and PMN (white bar) having ingested at least one particle of malaria pigment. Results are the mean \pm SD from 4 infected NOD/SCID mice. (C) Representative Giemsa staining of different organs smears performed 45 days post-infection from 3 different NOD/SCID mice (upper panel left and right: peritoneum; lower left panel: spleen, lower right panel: liver). Arrows indicate haemozoin loaded MP. (D) Effect of clo-lip and NIMP-R14 antibody on HuRBC grafting in NOD/SCID peripheral blood. HuRBC are injected alone (Black square) or in combination with clo-lip (plain circle) or with NIMP-R14 antibody (open circle). Black arrows represent the days of injection. Results are means \pm SEM of 2 experiments ( $n=6$ mice per group). lower left panel) and in the liver (Fig 6C lower right panel). Moreover, clo-lip target only circulating $\mathrm{MO}$ and MP, and Figure 6D clearly shows that clo-lip is necessary for the grafting of HuRBC: the percentage of circulating HuRBC was $54 \pm 2 \%$ after three clo-lip injections $v s 0.95$ $\pm 0.93 \%$ without, or $4.1 \pm 2 \%$ with the anti-PMN NIMPR14 antibody. Altogether, these results point to the $\mathrm{MO} /$ MP lineage as the most efficient component in controlling the graft of $P$. falciparum infected HuRBC.

\section{Discussion}

Results confirm that innate defences are potent against xenografts and pathogens in mice lacking $\mathrm{T}, \mathrm{B}$ and NK cell functions, and provide an insight of their effect against $P$. falciparum in immunodeficient mice. Several years ago, our group has taken advantage of immunocompromized mice, i.e. mice genetically defective in their adaptive immunity, to generate a $P$. falciparum mouse model, which could be successfully used for several types of applications such as assessment of antibodies directed to new vaccine candidates $[6,7,11]$ or of anti-malarial drugs [8] with any $P$. falciparum strain or isolate [12]. The repeated injection into the peritoneum of HuRBC, clo-lip and NIMP-R14 antibody allowed P. falciparum growth in mouse peripheral blood, but at the expense of a high failure rate, since only a subset harboured a stable parasitaemia (i.e. 12\% among several hundred NOD/SCID mice tested have a stable parasitaemia and $37 \%$ have a recrudescent parasitaemia). Therefore, it was decided to focus further work on the analysis of murine innate immune defences induced by this very pro-inflammatory parasite in order to gather an understanding, i.e. to attempt to identify the critical defence component(s) limiting successful grafting.

The present study shows that 1) P. falciparum induces a major inflammation characterized by an increase in peripheral leukocytes and by the release of inflammatory cytokines in the serum; 2) parasitaemia in the peritoneum remains stable whereas the decrease observed in the peripheral blood is related to HuRBC clearance in this compartment, triggered by the parasite; 3) P. yoelii, induces a very moderate inflammation as compared to $P$. falciparum, suggesting that a parasite adapted to its host does not trigger the same inflammatory response (which may be related to host factors, for example a lower recognition by host receptors, and/or to parasite factors, for example a lower production of pro-inflammatory molecules presented by this parasite); 4) clo-lip, NIMP-R14 and $\mathrm{HuRBC}$ also induce an inflammation, but far less important than that triggered by the parasite itself, and the former is anyhow essential to parasite grafting; 5) none of the additional immunosuppressive, anti-inflammatory, anti-oxidant and nutritive factors assessed in empirical manner was able to significantly, or reproduc- 
ibly, improve P. falciparum survival; and 6) MP seem to bear the most critical function in controlling $P$. falciparum in these mice.

The innate immune defences that remain in immunocompromized mice have seldom been analysed. Surprisingly, only one study has so far focused on this issue. It reported the occurrence of a major inflammation in relation to human leukocytes grafting in SCID mouse peritoneum [13]. It consists in a massive and early (24 h) recruitment of neutrophils and in the secretion of a wide spectrum of murine cytokines, such as IL-6, TNF, IFN $\gamma$, IL-1 $\beta$, IL-10, IL-12p40 in the peritoneal cavity. The role of granulocytes is supported by improved engraftment of human leukocytes following administration of the antigranulocyte antibody RB6-8C5 [14]. Since this report, innate immune responses in immunocompromized mice have remained surprisingly little explored, despite the general agreement that they are very efficient in defence against xenografts $[15,16]$. Even NOD/SCID/IL-2r $\gamma^{-/-}$ mice, which present substantial additional defects in innate immunity (they lack functional T, B and NK cells, have reduced functions of MP and dendritic cells, and several cytokines pathways are totally impaired) still require the use of pharmacological agents or irradiation/ splenectomy to allow for the grafting of cells of human origin $[15,17]$.

The present study model includes a "double xenograft", of HuRBC and of P. falciparum. A first limitation of this model is the lack of understanding of the transperitoneal passage of both uninfected and infected HuRBC in mouse peripheral blood, and its lack of reproducibility (17\% of mice were negative). The i.p. route of administration of $\mathrm{HuRBC}$ was chosen as it was previously found effective using bovine $\mathrm{RBC}$ [2], as it constitutes a reservoir whereas HuRBC injected i.v. are quickly eliminated [18]. However, the mechanism of passage being unknown, though there are indications for lymphatic drainage $[19,20]$, the reasons for occasional blockade are even less clear. There might be a pure mechanical component as the simple increase in HuRBC volume $(2 \mathrm{ml}$ at $50 \%$ haematocrit daily) led us and others [21] to improve HuRBC chimerism in peripheral blood. Secondly, the increase of clearance of HuRBC (both infected and non-infected) 7 to 10 days after injection of the parasite, is likely inflammation dependent as it was found to be associated with a concomitant peak of inflammatory cytokines and chemokine (IL-12p70, IFN $\gamma$, TNF $\alpha$ and MCP-1) in mouse serum. TNF $\alpha$ is known to increase erythrophagocytosis and to induce anaemia during malaria both in mouse and in human [22]. Splenectomy improves HuRBC grafting, suggesting that splenic MP play a role in this clearance $[21,23]$. Thirdly, in those rare cases $(5 \%)$ when the peritoneum cavity was invaded by millions of MP this resulted in HuRBC phagocytosis, and clearance of the graft in this compartment.

Together these data suggest a prominent role of MP in the rejection of both uninfected and infected HuRBC by two main mechanisms: the release of inflammatory mediators reflecting the activation of $\mathrm{MO}$ and the resulting increased erythrophagocytosis. The role of MP in xenograft rejection is well documented [24]. For instance they account for the majority of infiltrating leukocytes during the rejection of pig-to-primate xenografts [25,26] and selective MP depletion in immunocompetent rodents resulted in significant delays in cellular infiltration and xenograft rejection $[27,28]$. Finally, clo-lip which depletes MO/MP was clearly essential to both HuRBC and P. falciparum survival, stressing also in this model the importance of MP.

The mechanism of HuRBC phagocytosis by murine MP is yet to be elucidated. It can not be due to complement or by $\mathrm{Fc}_{\mathrm{C}}$ receptors-mediated opsonization, as NOD/SCID mice have neither complement activity [29] nor antibodies [29,30]. C-type lectins integrated in MP membrane have been reported to mediate erythrophagocytosis by directly binding to sugar ligands on the surface of senescent or altered RBC [31,32]. Moreover, the signal regulatory protein a $(\mathrm{SIRP} \alpha)$ is a critical immune inhibitory receptor on MP that reacts with CD47 to prevent autologous phagocytosis. Since CD47 is species specific, healthy HuRBC may be phagocytozed by murine MP due to their inability to induce murine MP SIRP $\alpha$ tyrosine phosphorylation [33,34]. Conversely, phagocytosis of $P$. falciparum infected HuRBC by MP is well documented, and the scavenger receptor $\mathrm{CD} 36$, which recognizes PfEMP-1 on the surface of infected RBC, is widely implicated in this process. Indeed, $P$. falciparum phagocytosis decreases by $80 \%$ using blocking antibodies or CD36 $\%$ murine MP [35,36]. MP also possess a large array of pathogen-recognition receptors such as toll-like receptors (TLRs) that recognize P. falciparum GPI anchors, that are considered as key malaria pathogenicity factors $[37,38]$. TLR-2 and to a lesser extent TLR-4 directly recognize infected RBC [39] whereas TLR-9 recognize only the haemozoin pigment [40-42], but all trigger inflammation through the MyD88/NFkB pathway. Uric acid (derived from hypoxanthine accumulated by the parasite) has been recently reported to be another major inflammatory mediator involved in P. falciparum infection [43]. The effect of haemozoin pigment on MO/MP is debated as it was reported to impair their function such as blocking of phagocytosis [44-46], but also to be a potent proinflammatory agent. Indeed it can trigger the release of NO, TNF, IL-6, IL-1 $\beta$, MIP-1 $\alpha$, MIP- $1 \beta$, MIP-2, MCP-1 and of many other mediators after in vivo administration [47-49]. Successive effects, i.e. pro-inflammation fol- 
lowed by a relative anergy, may explain this apparent contradiction. Whatever the complexity of the inflammatory response induced by the parasite, it probably explains the present observation, also made by another group, that the injection of infected HuRBC induces a decrease of the number of circulating HuRBC, either infected or not. The results of the present study suggest that, whereas uninfected HuRBC induce a moderate inflammation, the parasite is a far more potent pro-inflammatory component leading to a significant phagocytosis of HuRBC (both infected and uninfected).

The remarkable efficiency of the innate immune system to control plasmodium infection is in keeping with observations in humans: indeed, the parasitaemia recorded in a primary malaria attack, in non-immune travellers, is usually quite modest, $0.1 \%$ on average (PLD, unpublished observations in 700 infected European travellers), whereas the theoretical $16 \times / 48 \mathrm{~h}$ multiplication rate would lead to heavy parasitaemia in the absence of strong innate defences. Results in NOD/SCID show similarities and differences with $P$. falciparum activation of innate defences in humans. Recent studies performed in P. falciparum infected and exposed individuals have shown a strong pro-inflammatory effect with an overall increase in intermediate and inflammatory MO expressing $\mathrm{CD}^{2} 6^{+}, \mathrm{mIFN} \gamma$ and 2- to 10 -fold increase in serum mediators, such as IL-6, IL-10, IFNY, TNF and MCP-1 [9]. However, two opposite phenotypes could be identified in humans, based on chemokine receptors expression, which corresponded to differences in activity in the antibody-dependent, MO-mediated ADCI mechanism of defence and with 10 fold differences in the resulting parasitaemia in humans [9]. These two opposite phenotypes can correspond either to true differences between two groups of individuals or, alternatively, to successive states of $\mathrm{MO}$ activation by the parasite at different time-points. One of the patterns observed in NOD/SCID mice, where parasitaemia and inflammation were followed by a decrease of both, brings support to the latter view and is reminiscent of the two states described in mouse MO exposed to haemozoin. Finally, the observation that the rodent parasite $P$. yoelii induces much less inflammation than the human parasite in mice challenges the general assumption that the evolution-driven adaptation of Plasmodium to their respective hosts depends mainly on the adaptive immune system, and indicates that the role of non-adaptive immunity should be taken in consideration. The fine molecular tuning of parasite molecules required for the adaptation through the co-evolution of the parasite with their usual host has most likely taken place for molecules interacting with the adaptive immune system ("antigens") and for molecules interacting with the innate defences. The numerous differences between $P$. yoelii and
P. falciparum observed in our study bring support to this hypothesis.

More generally, the results of the present study stress that a deficiency in adaptive immunity is far from being enough to ensure the success of xenografts. It is also essential to control innate defences (which can not be knocked out safely). In this respect, $P$. falciparum-SCID mice constitute a convenient model as the effect of innate defences is readily visible within hours, in contrast with other types of grafts (e.g. lymphocytes). However, innate immunity proved as efficient as it is difficult to control. Three strategies have been used for this purpose. Firstly, splenectomy improved P. falciparum survival in NOD/ SCID mice [18]. Secondly, the suicide-based approach developed by Van Rooijen with clo-lip [5], despite its paradoxical inflammatory effect, was nonetheless efficient at depleting MP. Clo-lip proved essential at successful grafting of P. falciparum erythrocytic stages as well as human hepatocytes and $P$. falciparum liver stages in UPA-SCID [50]. Yet, a single clo-lip i.p. injection led to an increase of leukocytes, an increase of the CD43- $\mathrm{CD} 62 \mathrm{~L}^{+} \mathrm{Ly}-6 \mathrm{C}^{+} \mathrm{MO}$ subset and an increase of IL- 6 and MCP-1. These results suggest that conclusions from studies using clo-lip in mice should be interpreted with care. A third, and likely more satisfactory, strategy relies on the generation of mice with improved genetic deficiency of innate immunity. In this respect, the NOD/SCID/IL2r $\gamma^{-1-}$ (NOG) mice open new perspectives $[1,51]$, but simultaneously stresses the need for further efforts in the same direction. Indeed, NOG mice are not as good recipient of human skin and artery as SCID/bg mice [15], and, NOG reconstituted with $\mathrm{CD} 34^{+}$haematopoietic stem cells did not sustain the development of human B cells, and most $T$ cells could neither proliferate nor produce IL-2 in response to antigenic stimulation [17]. These results indicate that further improvements in genetic deficiencies are necessary. This in turn implies to better identify the molecular mechanisms critical in graft rejection.

\section{Conclusions}

Taken together data presented in this study show that immunocompromized mice such as NOD/SCID mice in which the number of MP and PMN are controlled to a certain extent by repeated injection of clo-lip and NIMPR14 antibody respectively, are still able to mount substantial innate defences against xenografts, notably HuRBC and $P$. falciparum. Moreover, the immunomodulatory treatment itself induced inflammatory responses. These results indicate that the use of SCID mice to study human disease need to be carefully interpreted and that further improvements are required to obtain a mouse model fully receptive to grafts of foreign origin. 


\section{Additional material}

Additional file 1 Comparison of the effects of three anti-PMN monoclonal antibodies. (A) Peripheral blood parasitaemia in 3 different NOD/ SCID mice treated either with NIMP-R14 (plain circle, dotted line), RB6-8C5 (open circle) or $1 \mathrm{~A} 8$ (black square) monoclonal antibody at $10 \mathrm{mg} / \mathrm{kg}$. Black arrows represent injection of HuRBC + clo-clip and one of the three antiPMN antibodies. (B) Peritoneal blood parasitaemia obtained in the NOD/ SCID mice treated with different anti-PMN. (C) Percentages of CD11 b+ Ly$6 G^{+}$PMN in mouse peripheral blood following repeated administration of the anti-PMN monoclonal antibodies.

\section{Abbreviations}

HuRBC: Human red blood cells; MP: macrophage; MO: monocyte; PMN: polymorphonuclear; clo-lip: clodronate-loaded liposomes.

\section{Competing interests}

The authors declare that they have no competing interests.

\section{Authors' contributions}

LA planned and carried out the research, performed experiments and analysed the results, drafted and revised the manuscript. RKT performed experiments and helped to write the manuscript. PM has performed experiments concerning the use of different reagents to improve P. falciparum survival. NVR supplied the clo-lip to the lab. JLP was involved in revising the manuscript. PD revised the manuscript and was responsible for overall strategy. All authors read and approved the final manuscript.

\section{Acknowledgements}

We thank Karima Brahimi and Geneviève Milon for useful advices and. Christian Roussilhon for the statistical analysis.

This work was supported in greatest part by a grant from the European Union BioMalPar programme.

\section{Author Details}

'Laboratoire de Parasitologie Bio-Médicale, Institut Pasteur, 28, rue du Dr Roux, 75015 Paris, France, ${ }^{2}$ Current Address; James Mitchell Laboratory, Department of Genetics and Complex Diseases, Harvard School of Public Health, Boston MA, USA and ${ }^{3}$ Department of Molecular Cell Biology, VU University Medical Center, 1007 MB Amsterdam, the Netherlands

Received: 19 March 2010 Accepted: 9 July 2010

Published: 9 July 2010

\section{References}

1. Ito M, Kobayashi K, Nakahata T: NOD/Shi-scid IL2rgamma(null) (NOG) mice more appropriate for humanized mouse models. Current Top Microbiol Immunol 2008, 324:53-76.

2. Tsuji M, Ishihara C, Arai S, Hiratai R, Azuma I: Establishment of a SCID mouse model having circulating human red blood cells and a possible growth of Plasmodium falciparum in the mouse. Vaccine 1995 13:1389-1392.

3. Badell E, Pasquetto V, Van Rooijen N, Druilhe P: A mouse model for human malaria erythrocytic stages. Parasitol Today 1995, 11:235-237.

4. Lopez AF, Strath M, Sanderson CJ: Differentiation antigens on mouse eosinophils and neutrophils identified by monoclonal antibodies. $\mathrm{Br} J$ Haematol 1984, 57:489-494.

5. van Rooijen N, van Kesteren-Hendrikx E: "In vivo" depletion of macrophages by liposome-mediated "suicide". Methods Enzymo/ 2003, 373:3-16

6. Druilhe P, Spertini F, Soesoe D, Corradin G, Mejia P, Singh S, Audran R, Bouzidi A, Oeuvray C, Roussilhon C: A malaria vaccine that elicits in humans antibodies able to kill Plasmodium falciparum. PLOS Medicine 2005, 2:e344.

7. Singh S, Soe S, Mejia JP, Roussilhon C, Theisen M, Corradin G, Druilhe P. Identification of a conserved region of Plasmodium falciparum MSP3 targeted by biologically active antibodies to improve vaccine design. J Infect Dis 2004, 190:1010-1018.

8. Moreno A, Badell E, Van Rooijen N, Druilhe P: Human malaria in immunocompromised mice: new in vivo model for chemotherapy studies. Antimicrob Agents Chemother 2001, 45:1847-1853.
9. Chimma P, Roussilhon C, Sratongno P, Ruangveerayuth $R$, Pattanapanyasat K, Perignon JL, Roberts DJ, Druilhe P: A distinct peripheral blood monocyte phenotype is associated with parasite inhibitory activity in acute uncomplicated Plasmodium falciparum malaria. PLoS Pathogens 2009, 5:e1000631.

10. Rowe AW, Eyster E, Kellner A: Liquid nitrogen preservation of red blood cells for transfusion; a low glycerol-rapid freeze procedure. Cryobiology 1968, 5:119-128.

11. Badell E, Oeuvray C, Moreno A, Soe S, van Rooijen N, Bouzidi A, Druilhe P: Human malaria in immunocompromised mice: an in vivo model to study defense mechanisms against Plasmodium falciparum. J Exp Med 2000, 192:1653-1660.

12. Moreno A, Ferrer E, Arahuetes S, Eguiluz C, Van Rooijen N, Benito A: The course of infections and pathology in immunomodulated NOD/LtSzSCID mice inoculated with Plasmodium falciparum laboratory lines and clinical isolates. Int J Parasitol 2006, 36:361-369.

13. Santini SM, Rizza P, Logozzi MA, Sestili P, Gherardi G, Lande R, Lapenta C, Belardelli F, Fais S: The SCID mouse reaction to human peripheral blood mononuclear leukocyte engraftment. Neutrophil recruitment induced expression of a wide spectrum of murine cytokines and mouse leukopoiesis, including thymic differentiation. Transplantation 1995, 60:1306-1314.

14. Santini SM, Spada M, Parlato S, Logozzi M, Lapenta C, Proietti E, Belardelli F, Fais S: Treatment of severe combined immunodeficiency mice with anti-murine granulocyte monoclonal antibody improves human leukocyte xenotransplantation. Transplantation 1998, 65:416-420.

15. Kirkiles-Smith NC, Harding MJ, Shepherd BR, Fader SA, Yi T, Wang Y, McNiff JM, Snyder EL, Lorber MI, Tellides G, Pober JS: Development of a humanized mouse model to study the role of macrophages in allograft injury. Transplantation 2009, 87:189-197.

16. Takeuchi D, Jones VC, Kobayashi M, Suzuki F: Cooperative role of macrophages and neutrophils in host Antiprotozoan resistance in mice acutely infected with Cryptosporidium parvum. Infect Immun 2008, 76:3657-3663

17. Watanabe $Y$, Takahashi T, Okajima A, Shiokawa M, Ishii N, Katano I, Ito R, Ito M, Minegishi M, Minegishi N, Tsuchiya S, Sugamura K: The analysis of the functions of human B and T cells in humanized NOD/shi-scid/ gammac(null) (NOG) mice (hu-HSC NOG mice). Int Immunol 2009, 21:843-858

18. Moore JM, Kumar N, Shultz LD, Rajan TV: Maintenance of the human malarial parasite, Plasmodium falciparum, in scid mice and transmission of gametocytes to mosquitoes. J Exp Med 1995, 181:2265-2270

19. Courtice FC, Harding J, Steinbeck AW: The removal of free red blood cells from the peritoneal cavity of animals. The Australian Journal of Experimental Biology and Medical Science 1953, 31:215-225.

20. Flessner MF, Parker RJ, Sieber SM: Peritoneal lymphatic uptake of fibrinogen and erythrocytes in the rat. Am J Physiol 1983, 244:H89-96.

21. Angulo-Barturen I, Jimenez-Diaz MB, Mulet T, Rullas J, Herreros E, Ferrer $S_{\text {, }}$ Jimenez E, Mendoza A, Regadera J, Rosenthal PJ, Bathurst I, Pompliano DL, Gómez de las Heras F, Gargallo-Viola D: A murine model of falciparummalaria by in vivo selection of competent strains in nonmyelodepleted mice engrafted with human erythrocytes. PLOS ONE 2008, 3:e2252.

22. Clark IA, Chaudhri G: Tumour necrosis factor may contribute to the anaemia of malaria by causing dyserythropoiesis and erythrophagocytosis. Br J Haematol 1988, 70:99-103.

23. Ishihara C, Tsuji M, Hagiwara K, Hioki K, Arikawa J, Azuma I: Transfusion with xenogeneic erythrocytes into SCID mice and their clearance from the circulation. J Vet Med Sci 1994, 56:1149-1154.

24. Cadili A, Kneteman N: The role of macrophages in xenograft rejection. Transplantation proceedings 2008, 40:3289-3293.

25. Itescu S, Kwiatkowski P, Artrip JH, Wang SF, Ankersmit J, Minanov OP Michler RE: Role of natural killer cells, macrophages, and accessory molecule interactions in the rejection of pig-to-primate xenografts beyond the hyperacute period. Human Immunol 1998, 59:275-286.

26. Lin $Y$, Vandeputte $M$, Waer M: Natural killer cell- and macrophagemediated rejection of concordant xenografts in the absence of $T$ and $B$ cell responses. J Immunol 1997, 158:5658-5667.

27. Fox A, Koulmanda M, Mandel TE, van Rooijen N, Harrison LC: Evidence that macrophages are required for T-cell infiltration and rejection of fetal pig pancreas xenografts in nonobese diabetic mice. Transplantation 1998, 66:1407-1416. 
28. Wu GS, Korsgren O, Zhang JG, Song ZS, Van Rooijen N, Tibell A: Role of macrophages and natural killer cells in the rejection of pig islet xenografts in mice. Transplantation Proc 2000, 32:1069.

29. Shultz LD, Schweitzer PA, Christianson SW, Gott B, Schweitzer IB, Tennent B, McKenna S, Mobraaten L, Rajan TV, Greiner DL: Multiple defects in innate and adaptive immunologic function in NOD/LtSz-scid mice. $J$ Immunol 1995, 154:180-191.

30. Bosma GC, Custer RP, Bosma MJ: A severe combined immunodeficiency mutation in the mouse. Nature 1983, 301:527-530

31. Muller E, Schroder C, Schauer R, Sharon N: Binding and phagocytosis of sialidase-treated rat erythrocytes by a mechanism independent of opsonins. Hoppe-Seyler's Zeitschrift fur physiologische Chemie 1983, 364:1419-1429.

32. Sheiban $\mathrm{E}$, Gershon $\mathrm{H}$ : Recognition and sequestration of young and old erythrocytes from young and elderly human donors: in vitro studies. $J$ Lab Clin Med 1993, 121:493-501.

33. Oldenborg PA, Zheleznyak A, Fang YF, Lagenaur CF, Gresham HD, Lindberg FP: Role of CD47 as a marker of self on red blood cells. Science 2000, 288:2051-2054.

34. Wang H, VerHalen J, Madariaga ML, Xiang S, Wang S, Lan P, Oldenborg PA, Sykes M, Yang YG: Attenuation of phagocytosis of xenogeneic cells by manipulating CD47. Blood 2007, 109:836-842.

35. Patel SN, Lu Z, Ayi K, Serghides L, Gowda DC, Kain KC: Disruption of CD36 impairs cytokine response to Plasmodium falciparum glycosylphosphatidylinositol and confers susceptibility to severe and fatal malaria in vivo. J Immunol 2007, 178:3954-3961.

36. Patel SN, Serghides L, Smith TG, Febbraio M, Silverstein RL, Kurtz TW, Pravenec M, Kain KC: CD36 mediates the phagocytosis of Plasmodium falciparum-infected erythrocytes by rodent macrophages. J Infect Dis 2004, 189(2):204-213.

37. Naik RS, Branch OH, Woods AS, Vijaykumar M, Perkins DJ, Nahlen BL, Lal AA, Cotter RJ, Costello CE, Ockenhouse CF, Davidson EA, Gowda DC: Glycosylphosphatidylinositol anchors of Plasmodium falciparum: molecular characterization and naturally elicited antibody response that may provide immunity to malaria pathogenesis. J Exp Med 2000, 192:1563-1576.

38. Schofield L, Hackett F: Signal transduction in host cells by a glycosylphosphatidylinositol toxin of malaria parasites. J Exp Med 1993, 177:145-153.

39. Krishnegowda G, Hajiar AM, Zhu J, Douglass EJ, Uematsu S, Akira S, Woods AS, Gowda DC: Induction of proinflammatory responses in macrophages by the glycosylphosphatidylinositols of Plasmodium falciparum: cell signaling receptors, glycosylphosphatidylinositol (GPI) structural requirement, and regulation of GPI activity. J Biol Chem 2005, 280:8606-8616.

40. Coban C, Ishii KJ, Kawai T, Hemmi H, Sato S, Uematsu S, Yamamoto M, Takeuchi O, Itagaki S, Kumar N, Horii T, Akira S: Toll-like receptor 9 mediates innate immune activation by the malaria pigment hemozoin. J Exp Med 2005, 201:19-25.

41. Parroche P, Lauw FN, Goutagny N, LatzE, Monks BG, Visintin A, Halmen KA, Lamphier M, Olivier M, Bartholomeu DC, Gazzinelli RT, Golenbock DT: Malaria hemozoin is immunologically inert but radically enhances innate responses by presenting malaria DNA to Toll-like receptor 9 . Proc Natl Acad Sci USA 2007, 104:1919-1924.

42. Tachado SD, Gerold P, McConville MJ, Baldwin T, Quilici D, Schwarz RT, Schofield L: Glycosylphosphatidylinositol toxin of Plasmodium induces nitric oxide synthase expression in macrophages and vascular endothelial cells by a protein tyrosine kinase-dependent and protein kinase C-dependent signaling pathway. J Immunol 1996, 156:1897-1907.

43. Orengo JM, Leliwa-Sytek A, Evans JE, Evans B, van de Hoef D, Nyako M, Day $\mathrm{K}$, Rodriguez A: Uric acid is a mediator of the Plasmodium falciparuminduced inflammatory response. PLoS One 2009, 4:e5194.

44. Morakote N, Justus DE: Immunosuppression in malaria: effect of hemozoin produced by Plasmodium berghei and Plasmodium falciparum. International Arch Allergy Immunol 1988, 86:28-34

45. Schwarzer E, Turrini F, Ulliers D, Giribaldi G, Ginsburg H, Arese P. Impairment of macrophage functions after ingestion of Plasmodium falciparum-infected erythrocytes or isolated malarial pigment. J Exp Med 1992, 176:1033-1041.
46. Schwarzer E, Skorokhod OA, Barrera V, Arese P: Hemozoin and the human monocyte--a brief review of their interactions. Parassitologia 2008, 50:143-145.

47. Huy NT, Trang DT, Kariu T, Sasai M, Saida K, Harada S, Kamei K: Leukocyte activation by malarial pigment. Parasitol Int 2006, 55:75-81.

48. Jaramillo M, Plante I, Ouellet N, Vandal K, Tessier PA, Olivier M: Hemozoininducible proinflammatory events in vivo: potential role in malaria infection. J Immunol 2004, 172:3101-3110.

49. Skorokhod OA, Schwarzer E, Ceretto M, Arese P: Malarial pigment haemozoin, IFN-gamma, TNF-alpha, IL-1 beta and LPS do not stimulate expression of inducible nitric oxide synthase and production of nitric oxide in immuno-purified human monocytes. Malar $J$ 2007, 6:73.

50. Morosan S, Hez-Deroubaix S, Lunel F, Renia L, Giannini C, Van Rooijen N, Battaglia S, Blanc C, Eling W, Sauerwein R, Hannoun L, Belghiti J, Brechot C, Kremsdorf D, Druilhe P: Liver-stage development of Plasmodium falciparum, in a humanized mouse model. J Infect Dis 2006, 193:996-1004

51. Jimenez-Diaz MB, Mulet T, Viera S, Gomez V, Garuti H, Ibanez J, AlvarezDoval A, Shultz LD, Martinez A, Gargallo-Viola D, Angulo-Barturen I: Improved murine model of malaria using P. falciparum competent strains and non-myelodepleted NOD-scid IL2R\{gamma\}null mice engrafted with human erythrocytes. Antimicrol Agents Chemother 2009, 53(10):4533-4536

doi: $10.1186 / 1475-2875-9-197$

Cite this article as: Arnold et al., Analysis of innate defences against Plasmodium falciparum in immunodeficient mice Malaria Journal 2010, 9:197

\section{Submit your next manuscript to BioMed Central and take full advantage of:}

- Convenient online submission

- Thorough peer review

- No space constraints or color figure charges

- Immediate publication on acceptance

- Inclusion in PubMed, CAS, Scopus and Google Scholar

- Research which is freely available for redistribution
C BioMed Central 